\section{Kidney \\ Blood Pressure Research}

\title{
Study on the Clinical Significance and Related Factors of Thirst and Xerostomia in Maintenance Hemodialysis Patients
}

\author{
Wei-Feng Fan ${ }^{a}$ Qi Zhang ${ }^{a}$ Li-Hong Luo Jian-Ying Niuª Yong Gua,b \\ aDivision of Nephrology, the Fifth People's Hospital of Shanghai, Fudan University; ${ }^{b}$ Division of \\ Nephrology, Huashan Hospital, Fudan University, Shanghai, China
}

\section{Key Words}

Hemodialysis $•$ Thirst $•$ Xerostomia $・$ Inter dialytic weight gain $\bullet$ Quality of life

\begin{abstract}
Aims: To analyse the clinical significance and related factors of thirst and xerostomia and to find methods to alleviate thirst and xerostomia in maintenance hemodialysis (MHD) patients. Methods: Forty-two MHD patients were included for observational study and eleven patients were enrolled for crossover trial. Thirst was assessed by $100-\mathrm{mm}$ visual analog scales (VAS) and dialysis thirst inventory (DTI). Meanwhile, xerostomia was assessed by VAS and xerostomia inventory (XI). Depression, kidney disease quality of life (KDQOL), salivary flow rates and inter dialytic weight gain (IDWG) were measured. Data were analyzed by ANOVA and correlation coefficient was used to assess the correlations between continuous variables. The results of crossover trial were investigated by two-sample T-tests. Results: Strong positive correlations among DTI, VAS thirst score, XI and VAS xerostomia score were found $(P=0.000)$. Daily IDWG was positively correlated with VAS thirst score $(r=0.315, P=0.042)$ and $\operatorname{DTI}(r=0.391, P=0.010)$. UWS (unstimulated whole saliva) was negatively correlated with VAS xerostomia score ( $r=-$ $0.308, P=0.048)$. Residual urine output was negatively correlated with DTI $(r=-0.402, P=0.008)$, VAS xerostomia score $(r=-0.461, P=0.002)$ and XI $(r=-0.403, P=0.008)$. In the crossover trial, DTI, XI, IDWG2d, IDWG3d, VAS thirst and xerostomia score were significantly reduced by the use of chewing gum $(P=0.000,0.001,0.009,0.017,0.038,0.001)$. The VAS thirst score, DTI and IDWG3d were significantly reduced by receiveing straw $(P=0.016,0.003,0.049)$. Conclusion: Thirst and xerostomia might affect the quality of life in MHD patients. Both chewing gum and straw could decrease thirst and IDWG.
\end{abstract}

Copyright $(2013$ S. Karger AG, Basel

\section{Introduction}

Most patients with end-stage renal disease (ESRD) under hemodialysis appear multiple complications, especially cardiovascular disease [1]. High fluid intake from daily diet leads to high inter dialytic weight gain (IDWG) in patients during dialysis session. Long-term 
noncompliance to the fluid-restricted diet may bring patients chronic fluid-overload and induce complications including hypertension, acute pulmonary oedema, congestive heart failure and cardiovascular comorbidity [2,3]. Previous studies have shown that, even though patients are aware of the complications, about $80 \%$ patients refuse to comply with restrictions on liquids $[2,4-6]$. Thus, patients taking maintenance hemodialysis (MHD) have to pay attention to daily diet and accept strict fluid intake restrictions.

Researches find that a considerable number of MHD patients suffered from thirst, xerostomia and saliva reduction simultaneously [7-9]. Factors including high sodium intake, potassium depletion, increased blood urea, sugar and high angiotensin II (AngII) levels and psychologic factors, may cause thirst and high fluid intake of MHD patients $[2,4,7$, 10-14]. MHD patients with thirst may have high fluid intake [4, 14]. Xerostomia, another potential dipsogenic factor, is caused by the reduction of salivary flow, which leads to thirst and excess IDWG. Some studies [15, 16] observe that there exist an intimate association among thirst, xerostomia and IDWG in MHD patients. Bots et al. [17] evaluated the effects of chewing gum or saliva substitute on thirst, xerostomia and IDWG and found no change in IDWG index. Pilocarpine significantly alleviated the increased thirst and large IDWG in MHD patients during three-month clinical trial [18]. These findings suggest that saliva substitutes or gustatory and masticatory stimulations can potentially be applied to decrease thirst and xerostomia in the therapy of MHD patients, which may also increase the compliance to the fluid-restricted diet and result in a decreased IDWG and an improved quality of life subsequently.

In our study, we investigated the clinical significance and related factors between thirst and xerostomia, and the relationship among thirst, xerostomia and quality of life. The potential effects of using sugar-free chewing gum and straw on xerostomia, thirst and IDWG in MHD patients were also concluded in our study, which may provide a unique way on the improvement for MHD patients.

\section{Materials and Methods}

\section{Patients and study protocol}

This study was approved by ethics committees of the No.5 Hospital of Shanghai, Fudan University, Shanghai, China, and adhered to the Declaration of Helsinki. Informed consent was also obtained from each participant. The inclusion criteria were as follows: $\geq 5$ months on hemodialysis (HD); $\geq 18$ years of age; mentally and physically being able to participate and complete the study; with stable clinical conditions including stable dry weight and hematocrit. Patients who were possessing hemodynamic instability preventing sufficient ultrafiltration, hospitalization within the preceding 3-month, dementia or terminal diseases, logistic impossibility of investigation, and unwillingto participate in this study were excluded.

Finally, forty-two MHD patients undergoing HD were included in our study and observed in the dialysis center of the No.5 Hospital of Shanghai. Age, gender, underlying diseases, HD duration, dry weight, body mass index, urine output and blood pressure were recorded. The use of angiotensin converting enzyme inhibitor (ACEI) or angiotensin receptor blockers (ARB) was also recorded. Weekly removal of urea by dialysis (Kt / Vweek), normalized protein catabolic rate (nPCR), routine blood test, plasma osmotic pressure, and biochemistry values were measured.

The crossover trial lasted for 6 weeks. In total, eleven patients randomly received either chewing gum or straw to restrict fluid in the first 2 weeks. After a wash-out period of 2 weeks, another regimen (chewing gum or straw) was carried out for the last 2 weeks. The xylitol sugar-free gum with minty flavor (Extra, Wrigley) and plastic straws with a diameter of $3 \mathrm{~mm}$ were selected and given to the patients. The participants were instructed to chew one piece of gum gently, for at least 10 minutes, six times a day and as desired throughout the day when the mouth felt dry or when they were thirsty, from 6-10 pieces approximately. The straws were used to take a little water when patients were thirsty. Thirst and xerostomia were assessed at baseline and after each treatment period as well as salivary flow rates. The mean blood pressure and IDWG were also calculated during each study period. 


\section{Kidney Blood Pressure Research}

Fan/Zhang/Luo/Niu/Gu: Thirst and Xerostomia in MHD Patients

Assessment of thirst and xerostomia

Thirst was assessed by the dialysis thirst inventory (DTI) and 100-mm self-rating visual analog scales (VAS). DTI quantified the occurrence of thirst before, during and after dialysis, and perceived thirst during day and night [17]. Each item had a 5 point Likert-type scale ('never' = 1 to 'very often' $=5$ ). The responses to the five items were summed, which results in a score ranging from 5 (never thirsty) to 25 (very often thirsty). VAS was defined as the negative and the positive on the left and right, respectively (e.g., $100 \mathrm{~mm}=$ extremely thirst) [18].

Xerostomia was assessed by XI (xerostomia inventory) and VAS during the dialysis session. XI is a validated questionnaire consisted of 11 items, each with a 5 point Likert-scale ('never' = 1 to 'very often' $=5$ ) [17]. All participants completed XI and the responses to the 11 items were added, which resulted in a score ranging from 11 (no dry mouth) to 55 (extremely dry mouth) [18].

\section{Saliva collection}

In the observational study, unstimulated whole saliva (UWS) was collected before dialysis. All subjects were instructed to refrain from smoking, eating, drinking or tooth brushing at least $1 \mathrm{~h}$ prior to saliva collection. UWS was collected for 5 min using an established spitting technique [19, 20]. In the crossover trial, UWS and paraffin chewing-stimulated whole saliva (PC-SWS) were both collected before analysis. The method of collecting PC-SWS was the same as that of collecting UWS. During the saliva collection period, the subjects chewed a piece of tasteless parafilm $(5 \times 5 \mathrm{~cm}, 0.30 \mathrm{~g}$; Parafilm 'M'; American National CAL, Chicago, IL, USA) at their natural pace. Saliva volumes were determined gravimetrically (assuming $1 \mathrm{~g}=1 \mathrm{~mL}$ ), with saliva flow rates expressed in milliliters per minute $(\mathrm{mL} / \mathrm{min})$. The saliva collection was performed by a trained investigator who was blind to all clinical data [17].

\section{Assessment of IDWG}

Participants were weighed before and after each dialysis session. IDWG was defined as the amount of fluid (kg) removed during the dialysis session [17]. IDWG\% was obtained by dividing IDWG by the patient's target dry weight. The IDWG was expressed as daily IDWG, daily IDWG\%, IDWG for 2 day (IDWG 2d) and for 3 day (IDWG 3d) as indicated. The target dry weight of patient was determined according to standard clinical criteria and was reviewed continuously by nephrologists. To get better assessment of the changes of IDWG, we set the ultrafiltration rate according to the IDWG in each dialysis session and corrected the postdialysis body weight to the target dry weight. Given that patients we recruited were with stable dry weight during our study, the post-dialysis body weights were comparable with target dry weights [18]. Meanwhile, systolic blood pressure (SBP), diastolic blood pressure (DBP) and mean arterial blood pressure (MAP) were also detected.

\section{Assessment of KDQOL}

The Kidney Disease Quality of Life (KDQOL) [21] was assessed using the short version of the validated KDQOL-SF ${ }^{\mathrm{TM}}$ Version 1.3 Scoring Program(v3.0) (Copyright @UCLA Division Of General Internal Medicine and Health Services Research, 2000). This questionnaire contains 80 items, which included Kidney Disease Target Area (KDTA, 44 items) and Short Form 36 (SF-36, 36 items). The item scores were aggregated without weighting and transformed linearly to a 0-100 range. Patients with higher scores had better states.

\section{Statistical analysis}

In our study, data were expressed as mean \pm SD. The data were classified with regard to gender, age ( $<65$ and $\geq 65$ years), residual urine output (yes / no) and diabetics (yes / no). Data were analyzed by ANOVA and spearman correlation coefficient was used to assess the correlations between continuous variables. Factors including multiple linear regressions with stepwise selection were identified and independently associated with the score of VAS thirst, DTI, VAS xerostomia, and XI. The multivariate analyses were repeated forcing all variables left in the stepwise selection model, together with gender, age, the presence of diabetes, use of ACEI or ARB, nPCR, sodium, and potassium into the final regression model. In the crossover trial, the period effect and the influence of the order in which the subjects received the therapy (treatmentperiod interaction) were investigated with two-sample T-tests. Since no treatment-period interaction was found, we compared the effect of each therapy (chewing gum and straw) with the main baseline variables using the general linear model of ANOVA (repeated measures design, followed by paired T-tests as post-hoc 


\section{Kidney Blood Pressure Research}

Kidney Blood Press Res 2013;37:464-474

\begin{tabular}{l|l}
\hline DOI: 10.1159/000355717 & (C) 2013 S. Karger AG, Base
\end{tabular}

Published online: Oktober 22, 2013

www.karger.com/kbr
Table 1. Clinical data of 42 MHD patients in the cross-sectional study

\begin{tabular}{|c|c|}
\hline & Mean (SD) \\
\hline Age (years) & $65.2(10.9)$ \\
\hline Male gender & $57.1 \%(n=24)$ \\
\hline Residual urine output & $42.9 \%(n=18)$ \\
\hline Full denture & $16.7 \%(n=7)$ \\
\hline Current smoker & $4.8 \%(n=2)$ \\
\hline Alcohol use & $9.5 \%(n=4)$ \\
\hline \multicolumn{2}{|l|}{ Educational level } \\
\hline Primary school & $38.1 \%(n=16)$ \\
\hline Junior school & $38.1 \%(n=16)$ \\
\hline Senior school & $11.9 \%(n=5)$ \\
\hline University & $11.9 \%(n=5)$ \\
\hline Diabetes type 1 or 2 & $23.8 \%(n=10)$ \\
\hline Time on HD (months) & $38.5(25.4)$ \\
\hline \multicolumn{2}{|l|}{ HD sessions per week } \\
\hline 2 & $9.5 \%(n=4)$ \\
\hline 3 & $90.5 \%(n=38)$ \\
\hline \multicolumn{2}{|l|}{ HD sessions per week } \\
\hline Dry weight (kg) & $57.7(11.8)$ \\
\hline Body mass index $\left(\mathrm{kg} / \mathrm{m}^{2}\right)$ & $20.7(3.3)$ \\
\hline Daily IDWG (kg/d) & $0.9(0.4)$ \\
\hline Daily IDWG\% & $1.6(0.7)$ \\
\hline Pre-HD SBP (mmHg) & $147.0(20.4)$ \\
\hline Pre-HD DBP (mmHg) & $82.0(12.0)$ \\
\hline Pre-HD MAP (mmHg) & $103.2(13.7)$ \\
\hline $\operatorname{Hemoglobin}(\mathrm{g} / \mathrm{L})$ & $96.4(14.0)$ \\
\hline Serum albumin $(\mathrm{g} / \mathrm{L})$ & $42.4(3.6)$ \\
\hline $\mathrm{Kt} / \mathrm{V}$ & $1.4(0.3)$ \\
\hline nPCR (g/kg/day) & $1.3(0.3)$ \\
\hline DTI & $10.4(5.9)$ \\
\hline VAS thirst score & $33.7(31.0)$ \\
\hline $\mathrm{XI}$ & $19.5(7.9)$ \\
\hline VAS xerostomia score & $34.1(27.8)$ \\
\hline UWS (mL/min) & $0.26(0.21)$ \\
\hline
\end{tabular}

procedure). All statistical analyses were conducted using the statistical software package SPSS 13.0 at the two-tailed significance level of 0.05 .

\section{Results}

Observational study

Forty-two MHD patients (24 men and 18 women) were enrolled in the observational study. The mean age was $65.2 \pm 10.9$ years, and these patients were on HD for $38.8 \pm 25.4$ months. Causes for the chronic renal failure were glomerulonephritis (28.5\%), hypertension (21.4\%), diabetes (23.8\%), lupus nephritis (4.8\%), gouty nephropathy (4.8\%) and unknown (16.7\%). The clinical characteristics and pre-dialytic biochemical data at baseline were presented in Table 1.

Thirteen patients $(30.9 \%)$ were reported to appear thirst during daytime (fairly to very often). The mean DTI and VAS thirst score of the patients were $10.4 \pm 5.9$ and $33.7 \pm 31.0$, respectively. A subjective dry mouth was present in $69 \%$ of the patients. The mean XI and VAS xerostomia score of the patients were $19.5 \pm 7.9$ and $34.1 \pm 27.8$, respectively. About $26.2 \%$ patients of the study were reported to have problems with eating dry food, and $23.8 \%$ of the patients sipped liquids to aid in swallowing food. The mean UWS was 0.26 $\pm 0.21 \mathrm{~mL} / \mathrm{min}$. Normal values (0.25-0.50 mL / $\min$ ) were reported in $38.1 \%$ of the patients. Hyposalivation (UWS $<0.15 \mathrm{~mL} / \mathrm{min}$ ) was found in $40.5 \%$ of the cases.

Women had higher XI scores $(22.2 \pm 8.5)$ than men $(17.4 \pm 6.8 ; P=0.048)$. Participants with residual urine output reported significant lower scores of DTI, VAS thirst, XI and VAS xerostomia than subjects without residual urine output $(P<0.05$, Table 2$)$. DTI, VAS thirst score, XI and VAS xerostomia score were correlated with each other (Table3, $P=0.000$ ).

Correlates of DTI, VAS thirst score, XI, and VAS xerostomia score in the observational study were analysed ( Table 4). Daily IDWG was positively correlated with VAS thirst score $(\mathrm{r}=0.315, P=0.042)$ and DTI $(\mathrm{r}=0.391, P=0.010)$. Daily IDWG\% was positively correlated with VAS thirst score $(\mathrm{r}=0.519, P=0.000)$, DTI $(\mathrm{r}=0.490, P=0.001)$, VAS xerostomia score $(\mathrm{r}=0.384, P=0.012)$ and $\mathrm{XI}(\mathrm{r}=0.319, P=0.040)$. Residual urine output was negatively correlated with DTI $(\mathrm{r}=-0.402, P=0.008)$, VAS xerostomia score $(\mathrm{r}=-0.461, P=0.002)$ and XI $(\mathrm{r}=-0.403, P=0.008)$. Dry weight was negatively correlated with DTI $(\mathrm{r}=-0.317$, $P=0.041)$, VAS xerostomia score $(\mathrm{r}=-0.405, P=0.008)$ and XI $(\mathrm{r}=-0.403 P=0.008)$. UWS was negatively correlated with VAS xerostomia score $(\mathrm{r}=-0.308, P=0.048)$. The results of multiple linear regression analyses revealed that XI, VAS xerostomia score and daily IDWG\% were independently associated with DTI and VAS thirst score. No significant correlation was observed between UWS and IDWG. No significant interaction of gender, age, the presence of diabetes, use of ACEI or ARB was observed for thirst, xerostomia, IDWG, or salivary flow rate (data not shown).

The mean score of KDQOL-SF was $61.6 \pm 14.4$. The mean score of SF-36 and KDTA were $60.8 \pm 22.5$ and $62.4 \pm 10.7$, respectively. Compared with patients in low VAS thirst score 


\section{Kidney Blood Pressure Research}

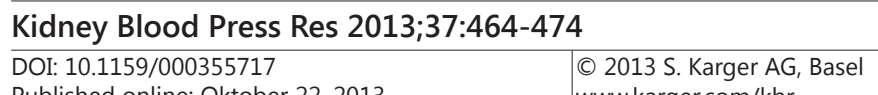

Published online: Oktober 22, 2013 www.karger.com/kbr

Table 2. Measurement of DTI, VAS thirst, XI, VAS xerostomia, UWS, Daily IDWG and Daily IDWG\% (data were expressed as mean $\pm \mathrm{SD}$ )

\begin{tabular}{|c|c|c|c|c|c|c|c|c|}
\hline & $\mathrm{n}$ & $\begin{array}{c}\text { DTI } \\
(5-25)\end{array}$ & $\begin{array}{l}\text { VAS Thirst } \\
\text { score }\end{array}$ & $\begin{array}{c}\mathrm{XI} \\
(11-55)\end{array}$ & $\begin{array}{c}\text { VAS } \\
\text { xerostomia } \\
\text { score } \\
\end{array}$ & $\begin{array}{c}\text { UWS } \\
\text { (mL/min) }\end{array}$ & $\begin{array}{c}\text { Daily } \\
\text { IDWG } \\
(\mathrm{Kg}) \\
\end{array}$ & $\begin{array}{l}\text { Daily } \\
\text { IDWG\% }\end{array}$ \\
\hline \multicolumn{9}{|l|}{ Gender } \\
\hline Male & 24 & $9.8 \pm 6.4$ & $32.3 \pm 33.9$ & $17.4 \pm 6.8$ & $27.4 \pm 25.6$ & $0.28 \pm 0.20$ & $1.0 \pm 0.4$ & $1.6 \pm 0.7$ \\
\hline Female & 18 & $11.1 \pm 5.4$ & $35.4 \pm 27.4$ & $22.2 \pm 8.5^{\mathrm{a}}$ & $43.0 \pm 28.9$ & $0.24 \pm 0.21$ & $0.8 \pm 0.4$ & $1.6 \pm 0.7$ \\
\hline \multicolumn{9}{|l|}{ Age group } \\
\hline$\geq 65$ years & 27 & $9.9 \pm 6.1$ & $27.1 \pm 31.0$ & $18.3 \pm 7.0$ & $30.9 \pm 25.9$ & $0.26 \pm 0.20$ & $1.5 \pm 0.6$ & $0.8 \pm 0.3$ \\
\hline$<65$ years & 15 & $11.3 \pm 5.8$ & $45.5 \pm 28.3$ & $21.5 \pm 9.2$ & $39.9 \pm 1.0$ & $0.26 \pm 0.23$ & $1.8 \pm 0.9$ & $1.1 \pm 0.5$ \\
\hline \multicolumn{9}{|c|}{ Urine output/d } \\
\hline$\geq 100 \mathrm{~mL}$ & 18 & $7.8 \pm 5.2$ & $22.6 \pm 31.6$ & $16.2 \pm 8.2$ & $20.1 \pm 28.2$ & $0.32 \pm 0.21^{\mathrm{b}}$ & $1.5 \pm 0.8$ & $0.9 \pm 0.4$ \\
\hline$<100 \mathrm{~mL}$ & 24 & $12.3 \pm 5.8^{a}$ & $42.0 \pm 28.4^{\mathrm{a}}$ & $21.9 \pm 6.9^{\mathrm{a}}$ & $44.6 \pm 22.9$ & $0.22 \pm 0.19$ & $1.7 \pm 0.6$ & $0.9 \pm 0.3$ \\
\hline \multicolumn{9}{|l|}{ DM } \\
\hline No & 32 & $10.1 \pm 5.8$ & $33.9 \pm 32.2$ & $18.4 \pm 7.3$ & $30.8 \pm 27.3$ & $0.27 \pm 0.22$ & $1.62 \pm 0.79$ & $0.9 \pm 0.4$ \\
\hline Yes & 10 & $11.4 \pm 6.6$ & $33.0 \pm 28.2$ & $22.7 \pm 9.2$ & $44.5 \pm 28.4$ & $0.22 \pm 0.14$ & $1.63 \pm 0.36$ & $1.0 \pm 0.3$ \\
\hline
\end{tabular}

Table 3. Correlations of DTI, VAS thirst score, XI and VAS xerostomia score in the observational study

\begin{tabular}{ccccccccc}
\hline & \multicolumn{2}{c}{ DTI } & \multicolumn{2}{c}{ VAS thirst score } & \multicolumn{2}{c}{ XI } & \multicolumn{3}{c}{ VAS xerostomia score } \\
\hline & $\mathrm{r}$ & $P$ & $\mathrm{r}$ & $P$ & $\mathrm{r}$ & $P$ & $\mathrm{r}$ & $P$ \\
\hline DTI & 1 & - & 0.840 & 0.000 & 0.682 & 0.000 & 0.759 & 0.000 \\
VAS Thirst score & 0.840 & 0.000 & 1 & - & 0.577 & 0.000 & 0.654 & 0.000 \\
XI & 0.682 & 0.000 & 0.577 & 0.000 & 1 & - & 0.977 & 0.000 \\
\hline
\end{tabular}

Table 4. Correlates of DTI, VAS thirst score, XI, and VAS xerostomia score in the observational study

\begin{tabular}{lcccccccc}
\hline & \multicolumn{2}{c}{ DTI } & \multicolumn{2}{c}{ VAS thirst score } & \multicolumn{2}{c}{ XI } & \multicolumn{3}{c}{ VAS xerostomia } \\
& $\mathrm{r}$ & $P$ & $\mathrm{r}$ & $P$ & $\mathrm{r}$ & $P$ & $\mathrm{r}$ & $P$ \\
\hline UWS & -0.149 & 0.348 & -0.170 & 0.281 & -0.293 & 0.060 & -0.308 & 0.048 \\
Daily IDWG & 0.315 & 0.042 & 0.391 & 0.010 & 0.124 & 0.434 & 0.180 & 0.255 \\
Daily IDWG\% & 0.490 & 0.001 & 0.519 & 0.000 & 0.319 & 0.040 & 0.384 & 0.012 \\
Urine output & -0.402 & 0.008 & -0.295 & 0.058 & -0.403 & 0.008 & -0.461 & 0.002 \\
Dry weight & -0.317 & 0.041 & -0.214 & 0.173 & -0.403 & 0.008 & -0.405 & 0.008 \\
SDS & 0.362 & 0.019 & 0.361 & 0.019 & 0.396 & 0.010 & 0.401 & 0.009 \\
\hline
\end{tabular}

Abreviation: SDS, self-rating depression scale

$(<50)$ group, high VAS thirst score $(>50)$ group had significant lower scores in many items of KDQOL-SF (Table 5). VAS thirst score, DTI, VAS xerostomia score and XI were negatively related with many items of KDQOL-SF (Table 6,7), such as symptom/problems list (SPL), effects of kidney disease (EKD), overall health $(\mathrm{OH})$ and emotional well-being (EWB). Multiple linear regression analyses showed that XI score, age and SDS were independent determinants for KDQOL.

\section{Crossover study}

In total, eleven MHD patients were enrolled and randomized to two groups: chewing gum and straw for 2 weeks. There were no significant difference in age, gender, time on HD, parameters of biochemistry, hemoglobin, Kt / V and nPCR between the two groups. What's more, no obvious difference was found in the level of xerostomia, thirst, IDWG and blood pressure. However, significant treatment effects were observed for thirst and xerostomia (Table 8). The use of chewing gum decreased the VAS thirst score $(70.7 \pm 17.1$ to $61.1 \pm 22.0$, $P=0.038)$, DTI $(19.3 \pm 3.4$ to $14.3 \pm 4.8, P=0.000)$, VAS xerostomia score (54.6 \pm 19.6 to $44.6 \pm 20.0, P=0.001)$ and XI $(32.2 \pm 9.4$ to $27.3 \pm 11.7, P=0.001)$. The use of straw also had a positive overall effect on the DTI $(P=0.016)$ and VAS thirst score $(P=0.003)$ during the crossover clinical trial. When patients treated with chewing gum, IDWG2d decreased from 


\section{Kidney Blood Pressure Research}

\section{Kidney Blood Press Res 2013;37:464-474}

DOI: 10.1159/000355717

Published online: Oktober 22, 2013

(C) 2013 S. Karger AG, Basel

www.karger.com/kbr

Table 5. Comparison of items of KDQOL stratified with VAS Thirst score ${ }^{\#}$

\begin{tabular}{lcccc}
\hline & $\begin{array}{c}\text { VAS thirst } \\
\text { score }<50(\mathrm{n}=30)\end{array}$ & $\begin{array}{c}\text { VAS thirst } \\
\mathrm{score} \geq 50(\mathrm{n}=12)\end{array}$ & Test type & $P$ \\
\hline Symptom/problems list (SPL) & $88.5 \pm 10.3$ & $72.7 \pm 23.3$ & $\mathrm{t}=2.263$ & 0.042 \\
Burden of kidney disease (BKD) & $73.5 \pm 17.7$ & $59.1 \pm 24.9$ & $\mathrm{t}=2.12$ & 0.040 \\
Overall health (OH) & $60.0(50.0,72.5)$ & $50.0(30.0,60.0)$ & $\mathrm{Z}=-2.4482$ & 0.016 \\
Emotional well-being (EWB) & $82.9 \pm 12.5$ & $64.0 \pm 25.8$ & $\mathrm{t}=2.430$ & 0.030 \\
Social function (SOCF) & $75.8 \pm 24.3$ & $54.2 \pm 37.8$ & $\mathrm{t}=2.212$ & 0.033 \\
SF-12 physical health (SF12MH) & $52.9 \pm 7.8$ & $45.2 \pm 13.3$ & $\mathrm{t}=2.331$ & 0.025 \\
Short Form 36 (SF-36) & $65.4 \pm 19.4$ & $49.2 \pm 26.3$ & $\mathrm{t}=2.203$ & 0.033 \\
Kidney Disease Target Area (KDTA) & $64.9 \pm 8.2$ & $56.0 \pm 13.6$ & $\mathrm{t}=2.615$ & 0.013 \\
KDQOL-SF & $65.1 \pm 11.3$ & $53.3 \pm 18.0$ & $\mathrm{t}=2.572$ & 0.014 \\
\hline
\end{tabular}

\#,The table only lists the items of KDQOL which had different comparison stratified with VAS thirst; 1, median (P25, P75); ${ }^{2}$, Mann-Whitney U

Table 6. Correlates of VAS thirst score, DTI with items of KDQOL in the observational study

\begin{tabular}{lcccc}
\hline & VAS thirst score (r) & $P$ & DTI & $P$ \\
\hline Symptom/problems list (SPL) & -0.442 & 0.003 & -0.547 & 0.000 \\
Effects of kidney disease (EKD) & -0.342 & 0.027 & -0.464 & 0.002 \\
Burden of kidney disease (BKD) & -0.220 & 0.162 & -0.417 & 0.006 \\
Overall health (OH) & -0.426 & 0.005 & -0.425 & 0.005 \\
General health (GH) & -0.277 & 0.076 & -0.433 & 0.004 \\
Emotional well-being (EWB) & -0.464 & 0.002 & -0.565 & 0.000 \\
Social function (SOCF) & -0.299 & 0.054 & -0.325 & 0.036 \\
Energy/Fatigue (EF) & -0.248 & 0.113 & -0.430 & 0.004 \\
SF-12 physical health (SF12PH) & -0.166 & 0.292 & -0.332 & 0.032 \\
SF-12 physical health (SF12MH) & -0.303 & 0.051 & -0.358 & 0.020 \\
Kidney Disease Target Area (KDTA) & -0.370 & 0.016 & -0.473 & 0.002 \\
Short Form 36 (SF-36) & -0.296 & 0.057 & -0.435 & 0.004 \\
KDQ0L-SF & -0.351 & 0.023 & -0.484 & 0.001 \\
\hline
\end{tabular}

Table 7. Correlates of VAS xerostomia score, XI with items of KDQOL in the observational study

\begin{tabular}{lcccc}
\hline & $\begin{array}{c}\text { VAS } \\
\text { xerostomia } \\
\text { Score (r) }\end{array}$ & $P$ & XI & $P$ \\
\hline Symptom/problems list (SPL) & -0.464 & 0.002 & -0.451 & 0.003 \\
Effects of kidney disease (EKD) & -0.441 & 0.003 & -0.425 & 0.005 \\
Burden of kidney disease (BKD) & -0.372 & 0.015 & -0.348 & 0.024 \\
Overall health (OH) & -0.532 & 0.000 & -0.494 & 0.001 \\
Role limitations-physical (RPL) & -0.312 & 0.044 & -0.301 & 0.052 \\
General health (GH) & -0.580 & 0.000 & -0.559 & 0.000 \\
Emotional well-being (EWB) & -0.470 & 0.002 & -0.446 & 0.003 \\
Social function (SOCF) & -0.319 & 0.040 & -0.306 & 0.049 \\
Energy/Fatigue (EF) & -0.472 & 0.002 & -0.477 & 0.001 \\
SF-12 physical health (SF12PH) & -0.385 & 0.012 & -0.407 & 0.007 \\
SF-12 physical health (SF12MH) & -0.384 & 0.012 & -0.387 & 0.011 \\
Kidney Disease Target Area (KDTA) & -0.460 & 0.002 & -0.451 & 0.003 \\
Short Form 36 (SF-36) & -0.500 & 0.001 & -0.519 & 0.000 \\
KDQOL-SF & -0.519 & 0.000 & -0.527 & 0.000 \\
\hline
\end{tabular}

$2.78 \pm 0.66 \mathrm{~kg}$ to $2.43 \pm 0.70 \mathrm{~kg}(P=0.009)$ and IDWG3d decreased from $3.17 \pm 0.89 \mathrm{~kg}$ to $2.88 \pm 0.65 \mathrm{~kg}(P=0.017)$. The IDWG3d also decreased by the use of straw to control water intake $(P=0.049)$. Treatment with chewing gum and straw did not influence UWS, PC-SWS, MAP, SBP and DBP during the crossover clinical trial. 


\section{Kidney Blood Pressure Research}

Table 8. The effect of the two treatment modalities on the main outcome variables in 11 MHD patients

\begin{tabular}{lccccc}
\hline & Baseline & Chewing gum & $P$ & Straw & $P$ \\
\hline VAS thirst & $70.7 \pm 17.1$ & $61.1 \pm 22.0$ & 0.038 & $59.4 \pm 21.7$ & 0.016 \\
DTI & $19.3 \pm 3.4$ & $14.3 \pm 4.8$ & 0.000 & $15.6 \pm 5.3$ & 0.003 \\
VAS xerostomia & $54.6 \pm 19.6$ & $44.6 \pm 20.0$ & 0.001 & $54.4 \pm 18.0$ & NS \\
XI & $32.2 \pm 9.4$ & $27.3 \pm 11.7$ & 0.001 & $30.0 \pm 10.1$ & NS \\
UWS & $0.20 \pm 0.16$ & $0.24 \pm 0.24$ & NS & $0.21 \pm 0.15$ & NS \\
PC-SWS & $0.59 \pm 0.28$ & $0.67 \pm 0.39$ & NS & $0.57 \pm 0.37$ & NS \\
IDWG2d (kg) & $2.78 \pm 0.66$ & $2.43 \pm 0.70$ & 0.009 & $2.60 \pm 0.86$ & NS \\
IDWG3d (kg) & $3.17 \pm 0.89$ & $2.88 \pm 0.65$ & 0.017 & $2.94 \pm 0.71$ & 0.049 \\
Daily IDWG (kg) & $1.17 \pm 0.36$ & $1.10 \pm 0.35$ & NS & $1.14 \pm 0.39$ & NS \\
Daily IDWG\% & $2.08 \pm 0.49$ & $1.95 \pm 0.44$ & NS & $2.01 \pm 0.48$ & NS \\
SBP(mmHg) & $148.57 \pm 13.66$ & $146.27 \pm 15.81$ & NS & $146.77 \pm 15.24$ & NS \\
DBP(mmHg) & $87.89 \pm 6.61$ & $86.80 \pm 8.08$ & NS & $86.08 \pm 8.81$ & NS \\
MAP(mmHg) & $108.12 \pm 8.43$ & $106.62 \pm 10.35$ & NS & $106.31 \pm 10.52$ & NS \\
\hline
\end{tabular}

Compared with the treantment of straw during the crossover clinical trial, the VAS xerostomia score significant decreased by the use of chewing gum $(P=0.06)$. Between the two interventions, no difference was found in DTI, VAS thirst score, XI, UWS, PC-SWS, IDWG, MAP, SBP and DBP (Table 9).

\section{Discussion}

Researches have found that a large number of MHD patients are accompanied with thirst, xerostomia and saliva reduction [7-9]. In our study, high thirst scores were observed in $30.9 \%$ MHD patients, which was lower than some other studies [16-18], which might be caused by lacking of enough cases. Meanwhile, a relatively large proportion of the MHD patients in our study had a dry mouth (69\%), which was in agreement with previous studies $[16,22]$. But the xerostomia scores in MHD patients in our study were lower than patients in other studies [16, 23]. MHD patients might have a light dipsia of lower degree, which might cause a lower score in XI xerostomia score.

General exocrine gland dysfunction had been described in MHD patients, including the reduced acid secretion, impaired peptic secretion, dry eyes, and cutaneous xerosis [9, 24, 25]. Measurement of UWS was the most reliable method for quantifying the salivary function [26]. The UWS index $(0.26 \pm 0.21 \mathrm{~mL} / \mathrm{min})$ of our patients was normal compared with healthy individuals ( 0.25 to $0.5 \mathrm{~mL} / \mathrm{min}$ ) [27] and to other studies in MHD patients [22]. In our study, $48.24 \%$ MHD patients were hyposalivation (UWS $\leq 0.16 \mathrm{~mL} / \mathrm{min}$ ). The calculated mean rates were normal due to a few HD patients with high flow rates. UWS didn't present a relationship with dialysis months, suggesting that dialysis might not affect saliva function. The mean salivary flow rates of patients in our study were significantly higher than that of patients received radiotherapy for head and neck tumors $(0.113 \mathrm{~mL} / \mathrm{min})$ [28], which was also accorded with recent study that salivary glands maintained their secretory capacity in patients under UWS and chewing-stimulating [17].

Thirst and xerostomia are related to UWS and the dysfunction of saliva can cause xerostomia $[8,9,16,18,22]$. In our study, we did not find the relationship between thirst and UWS, suggesting that thirst might not be mainly caused by salivary flow rates reduction. Some studies observed thirst and xerostomia were significantly related to age, gender, depression, anxiety and stress [29, 30]. Other study showed MHD patients under the age of 65 years had much higher XI scores [16]. Our research showed that SDS score had an apparent relationship with thirst and xerostomia score, and XI score of female patients was significantly higher than male patients, and thirst and xerostomia were rarer in elder patients. 


\section{Kidney \\ Blood Pressure Research}

Kidney Blood Press Res 2013;37:464-474

\begin{tabular}{l|l}
\hline DOI: 10.1159/000355717 & (C) 2013 S. Karger AG, Base
\end{tabular}

Published onlıne: Oktober 22, 2013

www.karger.com/kbr

Fan/Zhang/Luo/Niu/Gu: Thirst and Xerostomia in MHD Patients
Table 9. Comparison of the effect of the two treatment modalities (chewing gum and straw for 2 weeks) on the main outcome variables

\begin{tabular}{|c|c|c|c|c|}
\hline & & $\begin{array}{l}\text { First stage } \\
\text { (2weeks) }\end{array}$ & $\begin{array}{c}\text { Second stage } \\
(2 \text { weeks })\end{array}$ & $P$ \\
\hline \multirow[t]{2}{*}{ VAS thirst score } & C-S & $57.8 \pm 25.5$ & $54.2 \pm 25.6$ & 0.853 \\
\hline & S-C & $65.6 \pm 16.6$ & $65.0 \pm 19.0$ & \\
\hline \multirow[t]{2}{*}{ DTI } & C-S & $14.2 \pm 6.5$ & $15.0 \pm 5.6$ & 0.179 \\
\hline & S-C & $16.4 \pm 5.6$ & $14.4 \pm 2.3$ & \\
\hline \multirow[t]{2}{*}{ VAS xerostomia score } & C-S & $40.7 \pm 14.1$ & $51.8 \pm 15.6$ & 0.006 \\
\hline & S-C & $57.4 \pm 22.1$ & $49.2 \pm 26.6$ & \\
\hline \multirow[t]{2}{*}{$\mathrm{XI}$} & C-S & $31.5 \pm 14.4$ & $32.7 \pm 12.7$ & 0.075 \\
\hline & S-C & $26.8 \pm 5.5$ & $22.2 \pm 4.9$ & \\
\hline \multirow[t]{2}{*}{ UWS } & C-S & $0.26 \pm 0.27$ & $0.27 \pm 0.17$ & 0.583 \\
\hline & S-C & $0.15 \pm 0.11$ & $0.22 \pm 0.24$ & \\
\hline \multirow[t]{2}{*}{ PC-SWS } & C-S & $0.67 \pm 0.37$ & $0.60 \pm 0.37$ & 0.096 \\
\hline & S-C & $0.54 \pm 0.40$ & $0.67 \pm 0.45$ & \\
\hline \multirow[t]{2}{*}{ IDWG2d } & C-S & $2.13 \pm 0.43$ & $2.35 \pm 0.46$ & 0.078 \\
\hline & S-C & $2.90 \pm 1.17$ & $2.79 \pm 0.84$ & \\
\hline \multirow[t]{2}{*}{ IDWG3d } & C-S & $2.65 \pm 0.46$ & $2.74 \pm 0.51$ & 0.565 \\
\hline & S-C & $3.17 \pm 0.90$ & $3.15 \pm 0.79$ & \\
\hline \multirow[t]{2}{*}{ Daily IDWG } & C-S & $0.99 \pm 0.24$ & $1.06 \pm 0.28$ & 0.415 \\
\hline & $\mathrm{S}-\mathrm{C}$ & $1.24 \pm 0.51$ & $1.23 \pm 0.44$ & \\
\hline \multirow[t]{2}{*}{ Daily IDWG\% } & C-S & $2.00 \pm 0.47$ & $2.11 \pm 0.38$ & 0.503 \\
\hline & S-C & $1.89 \pm 0.59$ & $1.90 \pm 0.45$ & \\
\hline \multirow[t]{2}{*}{ SBP } & C-S & $139.07 \pm 11.60$ & $139.72 \pm 13.64$ & 0.819 \\
\hline & S-C & $155.23 \pm 13.58$ & $154.92 \pm 16.89$ & \\
\hline \multirow[t]{2}{*}{ DBP } & C-S & $82.18 \pm 6.00$ & $81.00 \pm 7.25$ & 0.724 \\
\hline & S-C & $92.18 \pm 6.55$ & $92.33 \pm 6.91$ & \\
\hline \multirow[t]{2}{*}{ MAP } & C-S & $101.14 \pm 7.32$ & $100.57 \pm 8.73$ & 0.880 \\
\hline & S-C & $113.20 \pm 8.53$ & $113.19 \pm 10.10$ & \\
\hline
\end{tabular}

In our study, DTI, XI and VAS xerostomia score were negatively related to residual urine output, which was similar to the result of previous study [17]. We also observed no correlation between thirst, xerostomia, IDWG, or salivary flow rate and the use of ACEI or ARB. One recent study also found chronic ACEI therapy was not effective in reducing thirst and IDWG [31, 32]. We found significant relationships among thirst, xerostomia and IDWG, suggesting that xerostomia and thirst might be one of the reasons that lead to higher fluid intake. Studies have showed thirst had a positive relation to IDWG [7,

33]. Bots et al. found thirst and xerostomia were associated with greater IDWG [16, 33]. Thus, alleviating xerostomia and thirst might be an intervention to decrease IDWG in MHD patients.

On the other hand, although there was a relationship among thirst, xerostomia and IDWG, no conclusion could provide an evidence that thirst and xerostomia leading to drinking or high IDWG. Some patients feel very thirsty but have the willpower to strict fluid intake restrictions. These patients may be very thirsty, but still have low IDWG [10]. López-Gómez et al. [34] reported that a greater IDWG was directly associated with a better nutritional status. Therefore, the percent of IDWG results in better long-term prognosis of the patients. The beneficial effects of IDWG on the nutritional status and prognosis were greater than the negative aspects that depended on its effects on blood pressure.

The KDQOL has been developed as a self-report measure for individuals with kidney disease and on dialysis and the psychometric properties of the KDQOL-SF proved to be benefiting $[21,35]$. In our study, thirst and xerostomia were significantly negative correlation with many items of KDQOL-SF. What's more, XI and SDS were independent determinants for KDQOL. For patients on HD, a good correlation was observed between HRQOL and the levels of anxiety and depression $[36,37]$. Taskapan et al. found that all indices of quality of life decreased in MHD patients with depression [38]. Furthermore, renal transplantation enhanced salivary flow and decreased symptoms of xerostomia and thirst, and hence enhanced the potential to improve the quality of life of affected individuals [39]. Therefore alleviating thirst and xerostomia in MHD patients might improve their quality of life.

Patients on daily HD were less thirsty and also showed less fluctuation in body fluid volume [40]. But this therapy might not be used generally. In addition, xerostomia can be reduced by either stimulation of the saliva secretion (mechanical, gustatory, or pharmacologic) 


\section{Kidney \\ Blood Pressure Research}

or palliative care using mouthwashes or saliva substitutes [17, 24, 25]. In our crossover trial, the using of chewing gum for 2 weeks among MHD patients significantly reduced both thirst and xerostomia, which was agreed with other studies that investigated the effect of chewing gum on xerostomia in both MHD patients and other patient populations, such as rheumatic patients [41] or in patients with a malignant disease [17, 42, 43]. Furthermore, the use of straws to restrict fluid reduced perceived thirst in MHD patients but had no effect on xerostomia, which was similarly to the effect of saliva substitutes. Interestingly, we also found a minimal objective reduction in IDWG, which might not according perfectly with previous study that no change was found in IDWG [17]. However, some scholars had the view of their long-term use might irritate the oral tissue [11, 42, 44, 45]. In the 3-month clinical trial, Sung et al. found pilocarpine significantly alleviated the exaggerated thirst and large IDWG in MHD patients [18]. Therefore, the 2-week period might be short, and a longer study might affect fluid intake more significantly.

However, there were several limitations to our interventional trial. One potential limitation of this study was the lack of blinding. However, this was unavoidable in this crossover design in which the participant received two potential active agents (chewing gum and straw). In addition, only clinically stable patients were enrolled in our study. Therefore, it remained uncertain whether our findings could be generalized to individuals with multiple concurrent diseases.

\section{Conclusion}

Thirst was correlated with daily IDWG, daily IDWG\%, SDS, residual urine output and dry weight. UWS was negatively correlated with VAS xerostomia score. Xerostomia and IDWG were independently associated with thirst. Thirst and xerostomia were negatively correlated with many factors of KDQOL-SF. Besides, thirst and xerostomia might affect the quality of life in MHD patients. Chewing gum could alleviate thirst and xerostomia and the use of straw to restrict fluid could also alleviate thirst. Both of them could decrease IDWG. The use of chewing gum or straw could be considered as a clinical tool to assist MHD patients in improving compliance to the fluid intake restrictions, reducing cardiovascular diseases, avoiding possibly negative effect nutrition and improving their quality of life as well.

\section{Conflict of Interests}

We have no conflict of interest to state.

\section{Acknowledgements}

This study was supported by the Fudan University "985" hospital key discipline construction project (2012FDYSXK02) and by Minhang Distric key department construction project. And by the No.5 Hospital of Shanghai, Fudan University, Shanghai, China. We appreciated the help of hemodialysis unit staffs in the No.5 Hospital of Shanghai. We are also very greatful to the hemodialysis patients for their participating.

\section{References}

1 Saad TF, Hentschel DM, Koplan B, Wasse H, Asif A, Patel DV, Salman L, Carrillo R, Hoggard J: Cardiovascular implantable electronic device leads in CKD and ESRD patients: review and recommendations for practice. Semin Dial 2013;26:114-123. 


\section{Kidney \\ Blood Pressure Research}

Fan/Zhang/Luo/Niu/Gu: Thirst and Xerostomia in MHD Patients

-2 Kimmel PL, Varela MP, Peterson RA, Weihs KL, Simmens SJ, Alleyne S, Amarashinge A, Mishkin GJ, Cruz I, Veis JH: Interdialytic weight gain and survival in hemodialysis patients: effects of duration of ESRD and diabetes mellitus. Kidney Int 2000;57:1141-1151.

- Nachman F, del Campo MP, Gonzalez A, Corzo L, Vazquez H, Sfoggia C, Smecuol E, Sanchez MI, Niveloni S, Sugai E, Maurino E, Bai JC: Long-term deterioration of quality of life in adult patients with celiac disease is associated with treatment noncompliance. Dig Liver Dis 2010;42:685-691.

-4 Taylor JB, Stern TA: Conflicts Between Consultants and Consultees: Causes, Consequences, and Corrective Actions. Psychosomatics DOI: doi: 10.1016/j.psym.2013.01.007.

$\rightarrow 5$ Betts DK, Crotty GD: Response to illness and compliance of long-term hemodialysis patients. ANNA J 1988;15:96-100.

6 Khalil AA, Darawad M, Al Gamal E, Hamdan-Mansour AM, Abed MA: Predictors of dietary and fluid nonadherence in Jordanian patients with end-stage renal disease receiving haemodialysis: a cross-sectional study. J Clin Nurs 2013;22:127-136.

7 Giovannetti S, Barsotti G, Cupisti A, Morelli E, Agostini B, Posella L, Gazzetti P, Dani L, Aloisi M, Antonelli A, et al.: Dipsogenic factors operating in chronic uremics on maintenance hemodialysis. Nephron 1994;66:413-420.

8 Kao CH, Hsieh JF, Tsai SC, Ho YJ, Chang HR: Decreased salivary function in patients with end-stage renal disease requiring hemodialysis. Am J Kidney Dis 2000;36:1110-1114.

-9 Postorino M, Catalano C, Martorano C, Cutrupi S, Marino C, Cozzupoli P, Scudo P, Zoccali C: Salivary and lacrimal secretion is reduced in patients with ESRD. Am J Kidney Dis 2003;42:722-728.

10 Mistiaen P: Thirst, interdialytic weight gain, and thirst-interventions in hemodialysis patients: a literature review. Nephrol Nurs J 2001;28:601-604, 610-603; quiz 614-605.

11 Rogers PW, Kurtzman NA: Renal failure, uncontrollable thirst, and hyperreninemia. Cessation of thirst with bilateral nephrectomy. JAMA 1973;225:1236-1238.

12 Molaison EF, Yadrick MK: Stages of change and fluid intake in dialysis patients. Patient Educ Couns 2003;49:5-12.

13 Procci WR: Dietary abuse in maintenance hemodialysis patients. Psychosomatics 1978;19:16-24.

14 Dorhout Mees EJ: Thirst in dialysis patients. Kidney Int 2005;67:1192; author reply 1192-1193.

15 Wirth JB, Folstein MF: Thirst and weight gain during maintenance hemodialysis. Psychosomatics 1982;23:1125-1127, 1130-1121, 1134.

-16 Bots CP, Brand HS, Veerman EC, Valentijn-Benz M, Van Amerongen BM, Valentijn RM, Vos PF, Bijlsma JA, Bezemer PD, Ter Wee PM, Amerongen AV: Interdialytic weight gain in patients on hemodialysis is associated with dry mouth and thirst. Kidney Int 2004;66:1662-1668.

17 Bots CP, Brand HS, Veerman EC, Korevaar JC, Valentijn-Benz M, Bezemer PD, Valentijn RM, Vos PF, Bijlsma JA, ter Wee PM, Van Amerongen BM, Nieuw Amerongen AV: Chewing gum and a saliva substitute alleviate thirst and xerostomia in patients on haemodialysis. Nephrol Dial Transplant 2005;20:578-584.

18 Sung JM, Kuo SC, Guo HR, Chuang SF, Lee SY, Huang JJ: Decreased salivary flow rate as a dipsogenic factor in hemodialysis patients: evidence from an observational study and a pilocarpine clinical trial. J Am Soc Nephrol 2005;16:3418-3429.

19 Dawes C: Physiological factors affecting salivary flow rate, oral sugar clearance, and the sensation of dry mouth in man. J Dent Res 1987;66:648-653.

20 Gaviao MB, Engelen L, van der Bilt A: Chewing behavior and salivary secretion. Eur J Oral Sci 2004;112:1924.

21 Korevaar JC, Merkus MP, Jansen MA, Dekker FW, Boeschoten EW, Krediet RT, group NE-s: Validation of the KDQOL-SF: a dialysis-targeted health measure. Qual Life Res 2002;11:437-447.

22 Kho HS, Lee SW, Chung SC, Kim YK: Oral manifestations and salivary flow rate, pH, and buffer capacity in patients with end-stage renal disease undergoing hemodialysis. Oral Surg Oral Med Oral Pathol Oral Radiol Endod 1999;88:316-319.

23 da Mata AD, da Silva Marques DN, Freitas FM, de Almeida Rato Amaral JP, Trindade RT, Barcelos FA, Vaz Patto JM: Translation, validation, and construct reliability of a Portuguese version of the Xerostomia Inventory. Oral Dis 2012;18:293-298.

24 Takahashi S, Morita T, Koda Y, Murayama H, Hirasawa Y: Gastrointestinal involvement of dialysis-related amyloidosis. Clin Nephrol 1988;30:168-171. 


\section{Kidney \\ Blood Pressure Research}

Kidney Blood Press Res 2013;37:464-474

\begin{tabular}{l|l}
\hline DOI: 10.1159/000355717 & (C) 2013 S. Karger AG, Base
\end{tabular}

Published online: Oktober 22, 2013

www.karger.com/kbr

-25 Sachs EF, Bloch HM, Milne FJ: Pancreatic supplementation in end-stage renal disease. Nephron 1984;37:120-122.

-26 Preethi BP, Reshma D, Anand P: Evaluation of Flow Rate, pH, Buffering Capacity, Calcium, Total Proteins and Total Antioxidant Capacity Levels of Saliva in Caries Free and Caries Active Children: An In Vivo Study. Indian J Clin Biochem 2010;25:425-428.

-27 Navazesh M, Christensen C, Brightman V: Clinical criteria for the diagnosis of salivary gland hypofunction. J Dent Res 1992;71:1363-1369.

-28 Rieke JW, Hafermann MD, Johnson JT, LeVeque FG, Iwamoto R, Steiger BW, Muscoplat C, Gallagher SC: Oral pilocarpine for radiation-induced xerostomia: integrated efficacy and safety results from two prospective randomized clinical trials. Int J Radiat Oncol Biol Phys 1995;31:661-669.

-29 Nederfors T, Isaksson R, Mornstad H, Dahlof C: Prevalence of perceived symptoms of dry mouth in an adult Swedish population--relation to age, sex and pharmacotherapy. Community Dent Oral Epidemiol 1997;25:211-216.

-30 Bergdahl M, Bergdahl J: Low unstimulated salivary flow and subjective oral dryness: association with medication, anxiety, depression, and stress. J Dent Res 2000;79:1652-1658.

-31 Masajtis-Zagajewska A, Nowicki M: Influence of dual blockade of the renin-angiotensin system on thirst in hemodialysis patients. Nephron Clin Pract 2009;112:c242-247.

-32 Yang LY, Yates P, Chin CC, Kao TK: Effect of acupressure on thirst in hemodialysis patients. Kidney Blood Press Res 2010;33:260-265.

-33 Heidbreder E, Bahner U, Hess M, Geiger H, Gotz R, Kirsten R, Rascher W, Heidland A: [Regulation of thirst in end-stage kidney insufficiency]. Klin Wochenschr 1990;68:1127-1133.

>34 Lopez-Gomez JM, Villaverde M, Jofre R, Rodriguez-Benitez P, Perez-Garcia R: Interdialytic weight gain as a marker of blood pressure, nutrition, and survival in hemodialysis patients. Kidney Int Suppl 2005;93:S63-S68.

35 Hays RD, Kallich JD, Mapes DL, Coons SJ, Carter WB: Development of the kidney disease quality of life (KDQOL) instrument. Qual Life Res 1994;3:329-338.

36 Arenas MD, Alvarez-Ude F, Reig-Ferrer A, Zito JP, Gil MT, Carreton MA, Albiach B, Moledous A: Emotional distress and health-related quality of life in patients on hemodialysis: the clinical value of COOP-WONCA charts. J Nephrol 2007;20:304-310.

-37 Vazquez I, Valderrabano F, Jofre R, Fort J, Lopez-Gomez JM, Moreno F, Sanz-Guajardo D, Spanish Cooperative Renal Patients Quality of Life Study G: Psychosocial factors and quality of life in young hemodialysis patients with low comorbidity. J Nephrol 2003;16:886-894.

-38 Taskapan H, Ates F, Kaya B, Emul M, Kaya M, Taskapan C, Sahin I: Psychiatric disorders and large interdialytic weight gain in patients on chronic haemodialysis. Nephrology (Carlton) 2005;10:15-20.

-39 Bots CP, Brand HS, Poorterman JH, van Amerongen BM, Valentijn-Benz M, Veerman EC, ter Wee PM, Nieuw Amerongen AV: Oral and salivary changes in patients with end stage renal disease (ESRD): a two year follow-up study. Br Dent J 2007;202:E3.

40 Porcu M, Fanton E, Zampieron A: Thirst distress and interdialytic weight gain: a study on a sample of haemodialysis patients. J Ren Care 2007;33:179-181.

-41 Risheim H, Arneberg P: Salivary stimulation by chewing gum and lozenges in rheumatic patients with xerostomia. Scand J Dent Res 1993;101:40-43.

42 Davies AN: A comparison of artificial saliva and chewing gum in the management of xerostomia in patients with advanced cancer. Palliat Med 2000;14:197-203.

43 Gavalda C, Bagan J, Scully C, Silvestre F, Milian M, Jimenez Y: Renal hemodialysis patients: oral, salivary, dental and periodontal findings in 105 adult cases. Oral Dis 1999;5:299-302.

44 Higashi T, Hijikuro M, Yamagata K, Ogawa S: Influence of saliva flow rate stimulated by gum-chewing on salivary concentrations of catecholamine metabolites. Clin Chim Acta 2012;414:248-252.

45 Schultheiss OC: Effects of sugarless chewing gum as a stimulant on progesterone, cortisol, and testosterone concentrations assessed in saliva. Int J Psychophysiol 2013;87:111-114. 